\title{
Test Article and Test Plan for Heat-Pipe Gap-Conductance Testing
}

Jeremy Hartvigsen, Zachary Sellers, and Piyush Sabharwall Idaho National Laboratory

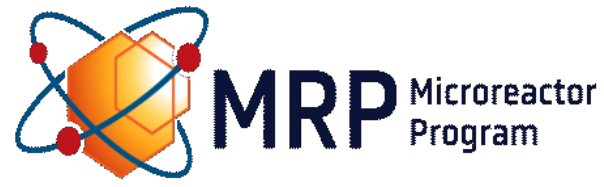




\section{DISCLAIMER}

This information was prepared as an account of work sponsored by an agency of the U.S. Government. Neither the U.S. Government nor any agency thereof, nor any of their employees, makes any warranty, expressed or implied, or assumes any legal liability or responsibility for the accuracy, completeness, or usefulness, of any information, apparatus, product, or process disclosed, or represents that its use would not infringe privately owned rights. References herein to any specific commercial product, process, or service by trade name, trade mark, manufacturer, or otherwise, does not necessarily constitute or imply its endorsement, recommendation, or favoring by the U.S. Government or any agency thereof. The views and opinions of authors expressed herein do not necessarily state or reflect those of the U.S. Government or any agency thereof. 


\title{
Test Article and Test Plan for Heat-Pipe Gap-Conductance Testing
}

Jeremy Hartvigsen, Zachary Sellers, and Piyush Sabharwall Idaho National Laboratory

April 2021

Idaho National Laboratory

Idaho Falls, Idaho 83415

http://www.inl.gov

\author{
Prepared for the \\ U.S. Department of Energy \\ Under DOE Idaho Operations Office \\ Contract DE-AC07-05ID14517
}




\section{ACKNOWLEDGMENTS}

This report was enhanced as a result of profitable discussions with Nuclear Regulatory Commission members, namely Steve Bajorek, Timothy Drzewiecki, Tarek Zaki and Joseph Kelly. The authors would like to thank them for their candor and support. 
Page intentionally left blank 


\section{CONTENTS}

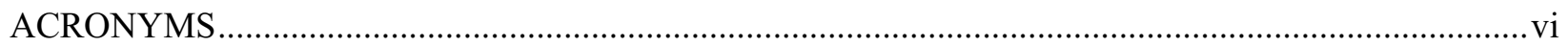

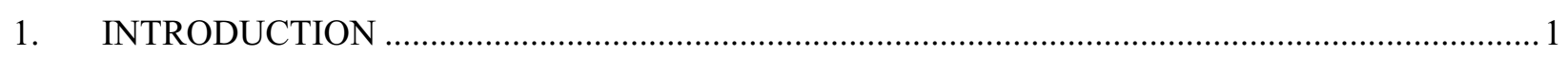

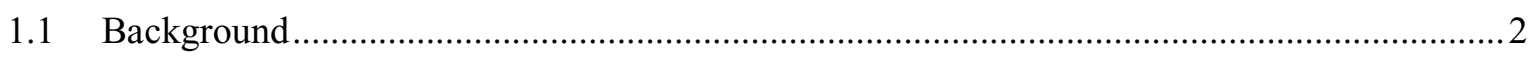

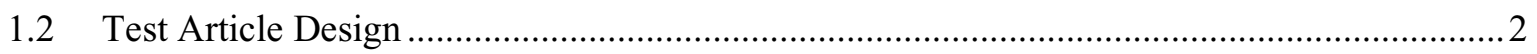

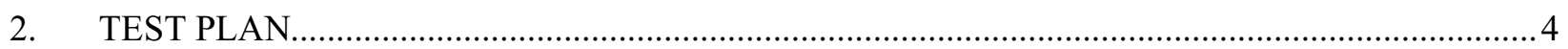

3. INTER-FUEL ELEMENT GAP CONDUCTANCE AND FAILED HEAT PIPE SIMULATION ...5

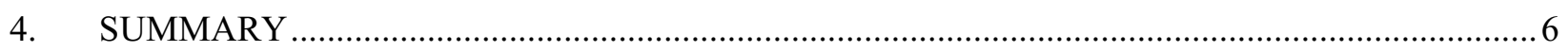

\section{FIGURES}

Figure 1. Process flow diagram of SPHERE Test Facility ..................................................................

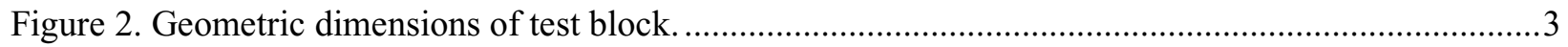

Figure 3. Configuration of SPHERE test stand with heat pipe, heaters, cooling shroud, and

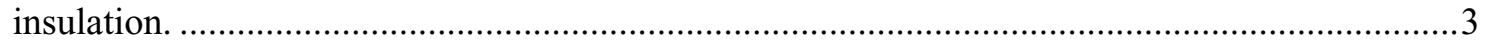

Figure 5. Heat pipe condenser end cooling shroud......................................................................

Figure 4. Thermal imaging examples of initial test article .....................................................................

Figure 6. Dummy heat pipe, acting as a failed heat pipe to determine boundary conditions in relation to an active heat pipe. .6

\section{TABLES}

Table 1. Test matrix for gap conductance testing. 
Page intentionally left blank 


\section{ACRONYMS}

ACT Advanced Cooling Technologies

INL Idaho National Laboratory

NEAMS Nuclear Energy Advanced Modeling and Simulation

SPHERE Single Primary Heat Extraction and Removal Equipment 
Page intentionally left blank 


\section{Test Article and Test Plan for Heat-Pipe Gap-Conductance Testing}

\section{INTRODUCTION}

The single primary heat extraction and removal emulator (SPHERE) Facility at INL is established to test phenomena related to heat pipes in nuclear applications. The current capability of the SPHERE testbed allows for better understanding of thermal performance of the liquid alkali-metal-cooled heat pipe under a wide range of heating values, variety of atmospheres and operating temperatures, further enhancing understanding of heat pipe startup and transient operation. The capability to control atmosphere can be used to prevent oxidation of system parts and also be used to affect the thermal conductivity of gases for any interfacial gaps within the heat-pipe assembly. Currently available modes are vacuum, air, nitrogen, helium, and argon. Controlled mixtures of helium and argon are available to vary the thermal conductivity of the gas. A process diagram with the major elements is shown in Figure 1. It is followed by a list of the major components in the SPHERE test bed. More information on SPHERE facility and its capabilities is provided in the SPHERE shakedown report ${ }^{\mathrm{a}}$

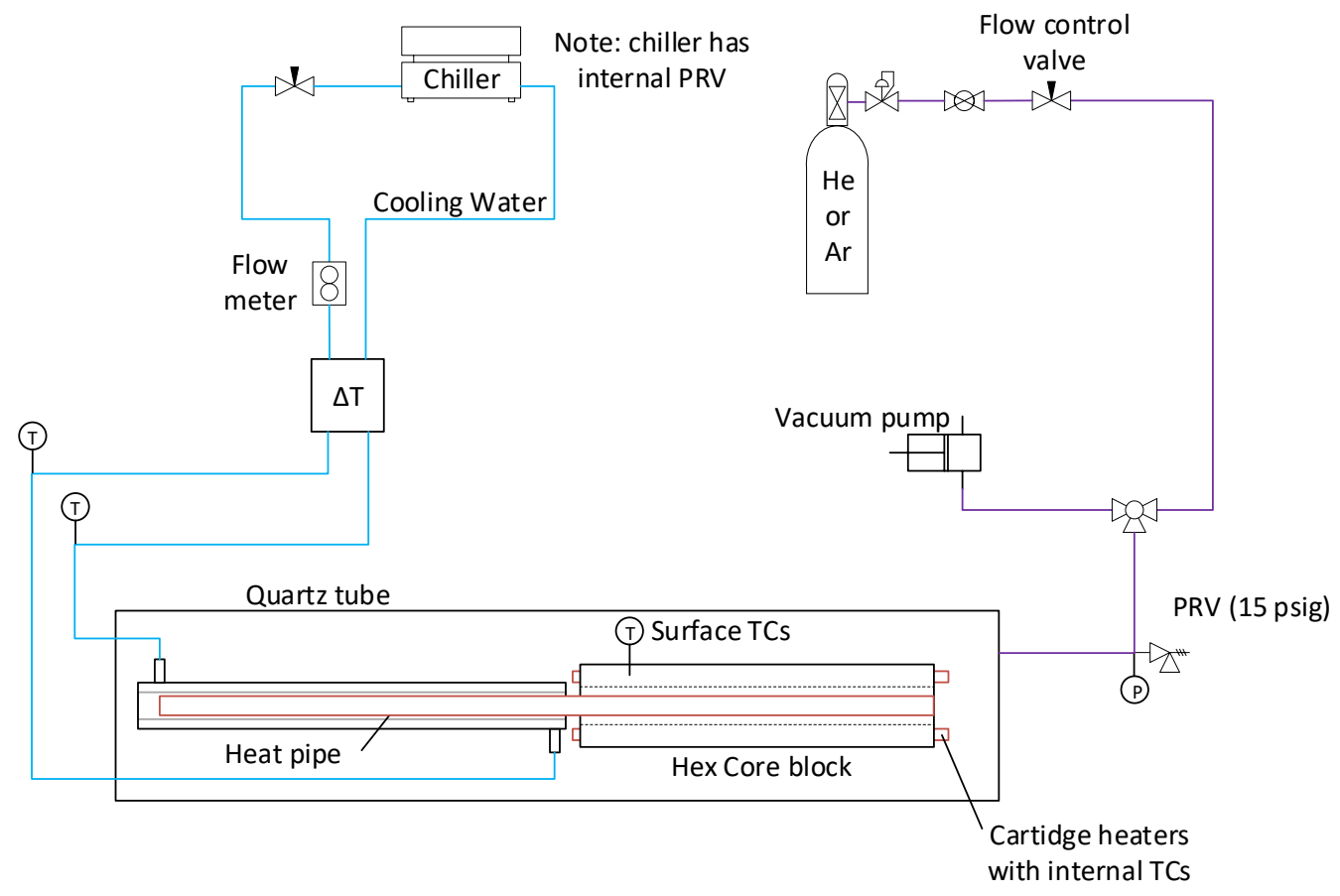

Figure 1. Process flow diagram of SPHERE Test Facility.

\section{SPHERE EQUIPMENT MAJOR EQUIPMENT LIST}

Following are the list of major equipment for the SPHERE facility:

Cartridge heaters

- Watlow FIREROD cartridge heaters

\footnotetext{
a Sabharwall, P., J. Hartvigsen, T. Morton, Z. Sellers, and J. S. Yoo, SPHERE Assembly and Operation Demonstration,
} INL/EXT-20-60782, Idaho National Laboratory, December 2020 
Power meters

- Ohio Semitronics, Model PC5-118X5Y25; single phase, 2-wire, 0-150 VAC, 0-25 A, 5-sec response for zero-crossing signal

Data Acquisition

- National Instruments PXI data-acquisition system

Power controllers

- Watlow Din-A-Mites, 100-240 VAC, 24 Amp, single-phase 4-20 mA control input

Temperature Control

- Watlow RMC temperature controllers

Water flow meter

- Flow Technology turbine flow meter, Model FTO-5NIXW-LHC-5 with linearization electronics, Linear Link RF input, 0-10 VDC output

High-temperature heat pipe

- $\quad$ ACT Heat Pipe

- Pipe material: SS 316

- Geometry: smooth-wall tube, proprietary wick

- Length: 2 m, Diameter: 0.625-in.

- Working fluid: sodium, non-condensable inert gas

- Wick: sintered stainless steel

- Operating temperature, $\sim 740^{\circ} \mathrm{C}$

- Heat-removal rating: $1 \mathrm{~kW}$

Vacuum Pump

- Small vacuum pump for removing air from test fixture (quartz tube enclosure), prior to back-fill with inert gas

Circulating water chiller

- ThermoFisher Thermoflex TF 2500, $2.5 \mathrm{~kW}$ cooling capacity, up to 4 gpm water flow rate.

\subsection{Background}

Heat pipes are passive phase-change heat-removal devices. They are of particular interest for microreactor applications. The lack of moving parts in heat pipes make them ideal for low-maintenance and safe operation. A variety of accident scenarios are being examined. Understanding of the complex physics of the heat pipe and its interaction with the reactor is crucial for establishing safe operation of heat pipes. In the event of heat-pipe failure, the thermal conductivity of the system across gaps between fuel elements is of importance to understand the heat removal capability for the system.

\subsection{Test Article Design}

The primary test article will be based on the existing SS-316 7-hole block design used for shakedown testing of the SPHERE Facility, as shown in Figure 2. The existing 7-hole blocks were produced via gundrilling by Holtec. These blocks have been characterized and have well-documented geometry. Several additional small grooves will be machined into the 7-hole block design in order to accommodate highdensity temperature sensors. The test article can use distributed Fiber Bragg temperature sensors, ultrasonic temperature sensors, and multipoint thermocouples. The spacing of these sensors can be as 
frequent as a sensor every several millimeters, to obtain axial temperature profile. Basic configuration of SPHERE test stand with heat pipe, core block, quartz tube, cooling shroud and insulation, is shown in Figures 2 and 3. The sensors will be housed in 1/16" OD capillary tubes and bonded into the small machined groves. The bonding agent will be a Cotronic 954 Durband stainless steel metallic bonding agent.

The ACT heat pipe is a sodium filled homogenous wick heat pipe. It has a small non-condensable gas reservoir. It also has a thermowell down the center. A multi-point thermocouple from Idaho Labs provides a type $\mathrm{K}$ thermocouple point every 6" in the thermowell.
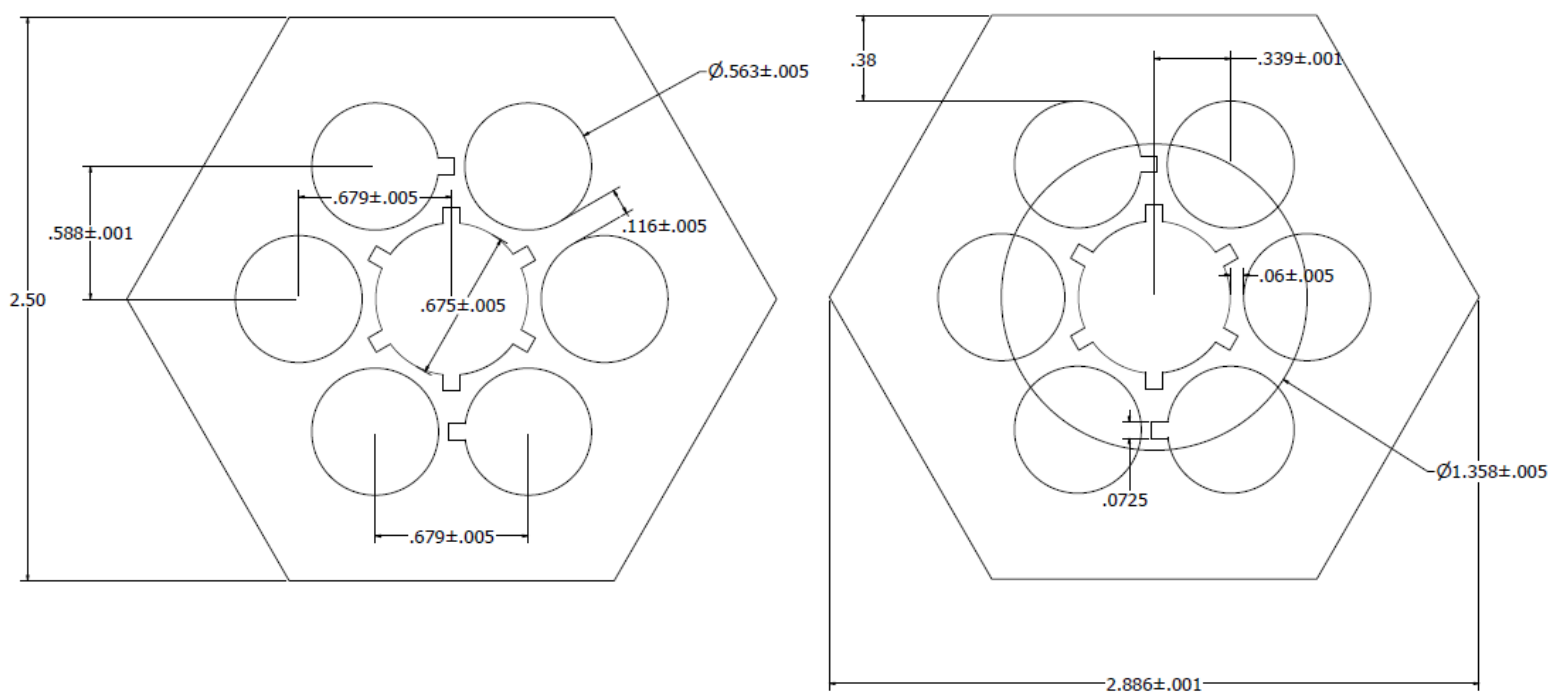

Figure 2. Geometric dimensions of test block.

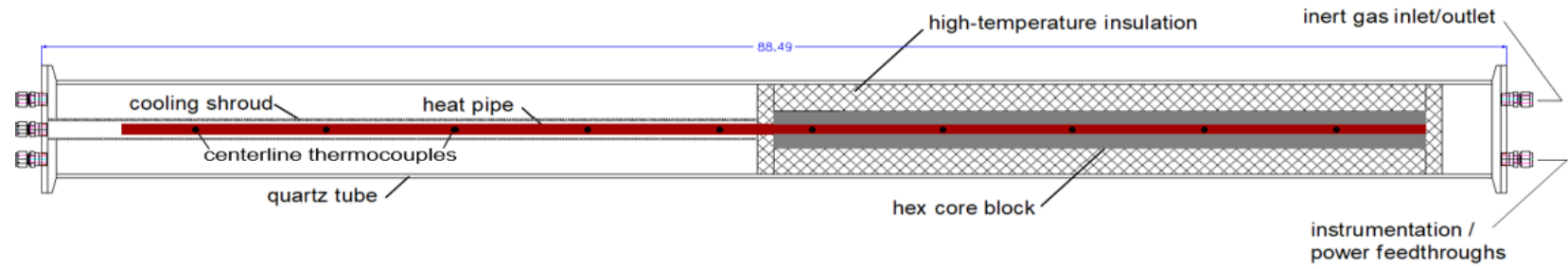

Figure 3. Configuration of SPHERE test stand with heat pipe, heaters, cooling shroud, and insulation.

The heat pipe will be loaded into the center hole. It will be centered in the hole by the use of small centering wires. The 1" lengths of the centering wires will be at the middle and ends of the heat pipe and block interface. This will provide minimal thermal contact between the heat pipe and the block. At the condenser end a cooling shroud will be used to provide a secondary check for calorimetry on the heat pipe, as shown in Figure 4. The cooling shroud consists of an annular flow path of water in a stainless steel tube. 


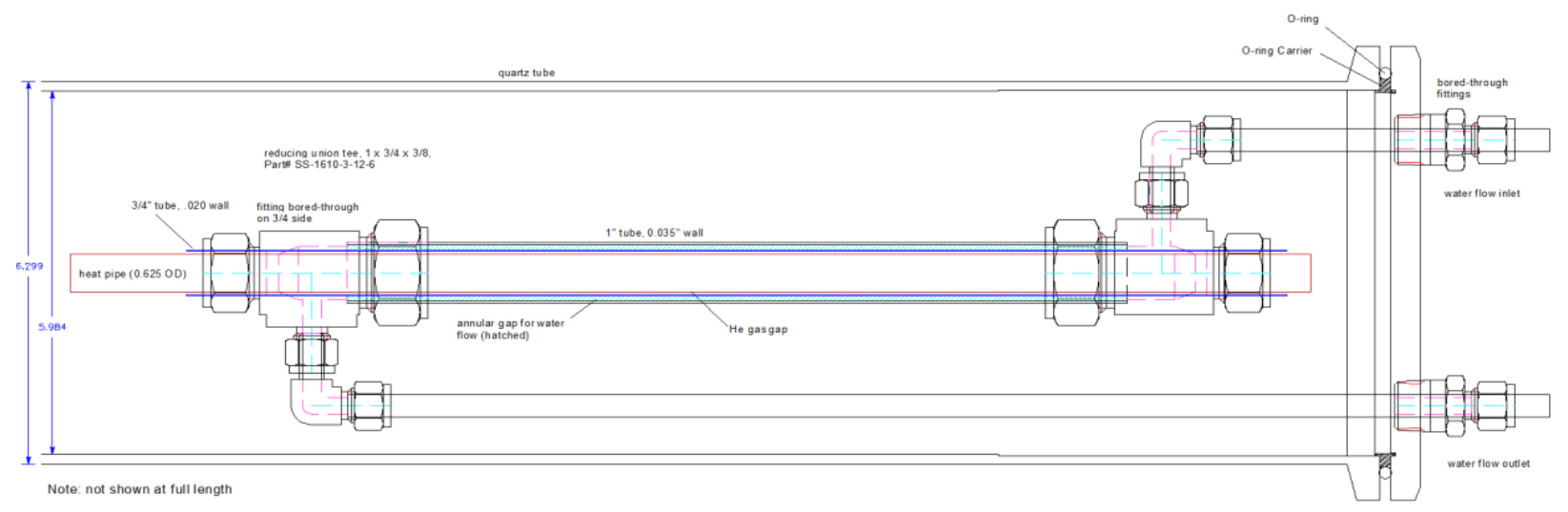

Figure 4. Heat pipe condenser and cooling shroud.

These temperature measurements will be used to establish thermal gradients that validate heat flow. Existing modeling tools have been used to establish a baseline for comparison between experimental and predicted results. Comparison between the results will be a follow-on activity of the testing.

\section{TEST PLAN}

The test bed will use calorimetry to measure the amount of heat rejected at the condenser end. Guard heaters will be used to simulate an adiabatic boundary condition to the exterior of the block. Thermal imaging cameras will be used to further evaluate the thermal boundary conditions of the exterior of the test-article block (see Figure ).

The plan for testing is to use the vacuum system to establish a baseline test that also verifies radiative heat-transfer variables such as surface emissivity. The next stage of testing will be varying the composition of the inert atmosphere to change thermal conductivity. Argon and helium ratios will be changed to examine the conductivity of the gap. The limiting case of vacuum should establish a safety baseline. Further characterization can be used to find the sensitivity of the system to the thermal coupling between the heat pipe and the inner wall. Prior to the testing, a handheld reflectometer will be used to character the emissivity of the surface.

After running the cases with a typical insulated block, a radiant heater setup will allow a specialized infrared camera to look at the system boundary in operando. The higher spatial resolution will be compared to physical measurements to verify the accuracy of the new measurement system.

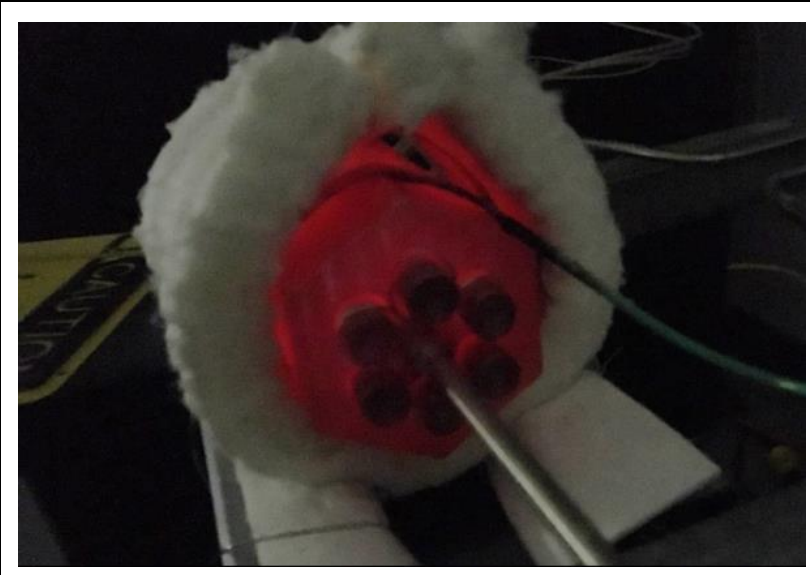

(a)

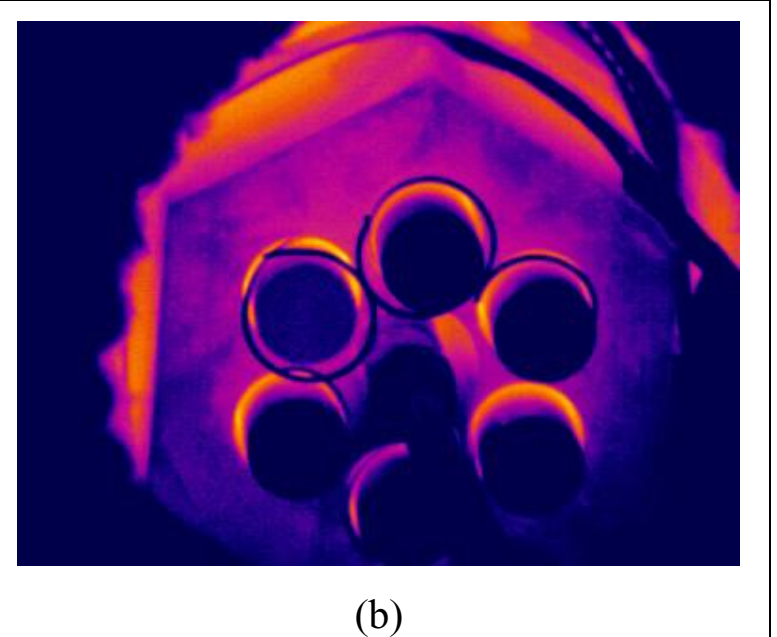

(b)

Figure 5. Thermal imaging examples of initial test article. 
The last phase of the experiment will be allowing oxidation of the system to change the emissivity of the heat pipe. The system will be in vacuum to characterize the new emissivity. The oxidized condition will provide another limiting case where a breach allows oxidation into the system.

Using the available resources and test system, the test matrix will be conducted with both an oxidized and non-oxidized system condition. A text matrix is given as Table 1.

Table 1. Test matrix for gap conductance testing.

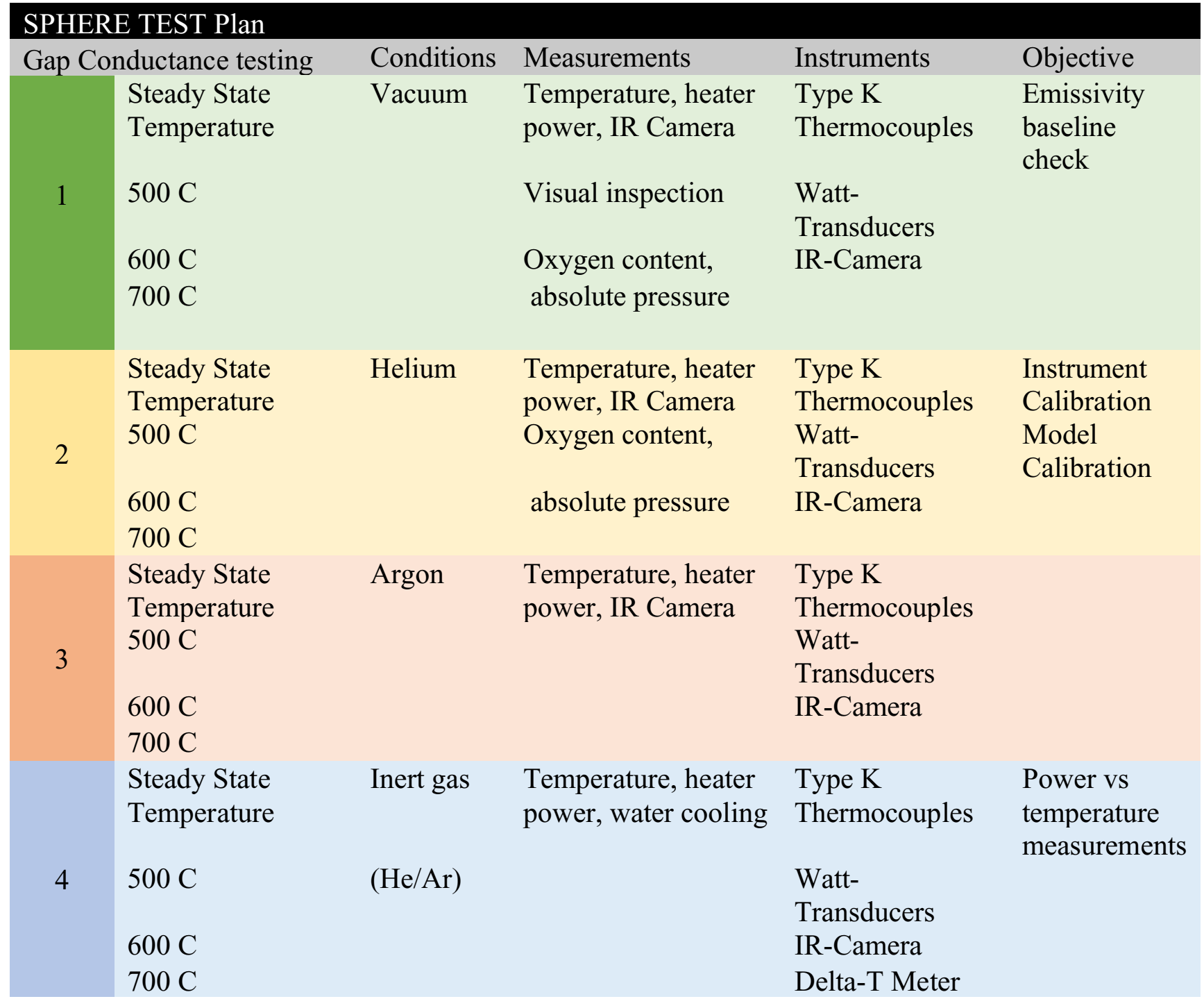

\section{INTER-FUEL ELEMENT GAP CONDUCTANCE AND FAILED HEAT PIPE SIMULATION}

Additional testing on the interlayer conductivity and the effects on the heat pipe can be explored by using an active heat pipe and a non-functional dummy heat pipe (Figure 2). The dummy heat pipe will 
serve as a failed heat pipe and the temperature boundary conditions will be controlled based on the measurements of the active heat pipe.

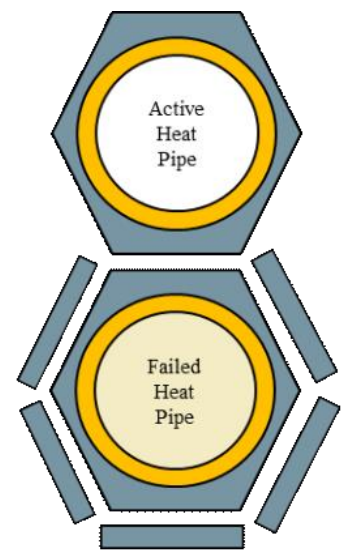

\section{Temperature controlled walls}

Figure 2. Dummy heat pipe, acting as a failed heat pipe to determine boundary conditions in relation to an active heat pipe.

The additional testing scope for testing a failed heat pipe condition is a testing activity after the conclusion of the main test activities. The needed equipment is all part of the existing test articles arranged and controlled with the main test setup equipment.

\section{SUMMARY}

The SPHERE test stand will be used with test articles to establish the conductivity between fuel elements as well as between the heat pipe and other layers of the fuel-rod assembly. Existing and new test blocks will be used and modified with additional instrumentation to establish the thermal conductivity between the gap of the block wall and the heat pipes. The existing Advanced Cooling Technologies (ACT) heat pipe will be used as the baseline heat pipe for the tests. Calorimetry and temperature measurements will be used to validate existing thermal models of the arrangement and provide required information to support verification and validation efforts for Nuclear Energy Advanced Modeling and Simulation (NEAMS) tools. 